\title{
Rapid high-performance liquid chromatographic quantification of recombinant human antithrombin III during production and purification
}

\author{
HF. Büntemeyer*, H. Tebbe, D. Lütkemeyer, J. Lehmann \\ Institute for Cell Culture Technology, University of Bielefeld, P.O. Box 1001 31, 33501 Bielefeld, Germany
}

First received 9 March 1994; revised manuscript received 24 May 1994

\begin{abstract}
For monitoring of recombinant human antithrombin III during cell culture processes and subsequent purification steps a rapid method for quantitative determination was developed. The need for the introduction of this rapid method came from the limited availability of a quantitative enzyme-linked immunosorbent assay (ELISA) and the very time-consuming ELISA procedure. The developed method is based on reversed-phase high-performance liquid chromatography using a $\mathrm{C}_{4}$ column. The separation by gradient elution using water and acetonitrile takes less than 20 min even when complex samples, such as serum ccntaining cell culture samples, have to be analyzed. Automation and a high sample throughput are possible with this reliavle method. If necessary, insulin, transferrin and albumin can also be quantified with minor changes of the elution profile.
\end{abstract}

\section{Introduction}

Antithrombin III (ATIII) is a plasma glycoprotein which is the major physiological regulator of several activated coagulation factors including thrombin, factor IXa, Xa, XIa, XIIa. ATIII is a member of the serine protease inhibitor (SERPIN) family with a molecular mass of about 60000 and about $15 \%$ carbohydrate content. The polypeptide chain consists of 432 amino acids and three disulphide bridges. The carbohydrate structure is split into four biantennary asparagine-linked chains.

ATIII is of some clinical importance for individuals with acquired or inherited deficiency of

\footnotetext{
* Corresponding author.
}

ATIII activity who suffer from a risk of venous thrombosis and pulmonary embolism [1]. In these cases a sufficient supply of pure ATIII can be necessary.

The protein can be purified from human plasma $[2,3]$. But, from the view of product safety and possible virus contamination (HIV, hepatitis) ATIII can also be produced by recombinant DNA technology. For this reason the human ATIII cDNA was isolated and expressed among others, in Chinese hamster ovary ( $\mathrm{CHO}$ ) cells. DHFR (dehydrofolate reductase)-deficient CHO ceils were cotranisfected with human ATIII cDNA and mouse DHFR cDNA [4]. Gene-amplified positive clones were obtained under selection pressure of increasing concentrations of the DHFR inhibitor MTX (4-amino-10-methyl folic 
acid, methotrexate). The $\mathrm{CHO}$ cells release the product into the surrounding medium. From that supernatant ATIII can be purified, especially if cells are cultured under serum-free conditions.

On the basis of the low expression level of the CHO cells it is necessary for the production of sufficient quantities of ATIII to use efficient bioreactor and purification systems as well.

In both cases a permanent and rapid control of product concentration and purity is required during the whole process. For monitoring of product concentration during fermentation an analytical tool based on enzyme-linked immunosorbent assay (ELISA) is available. The main disadvantages of ELISA methods are long preparation and measuring times and a high margin of error. During product purification the continual review of the decrease of impurities is very important. Electrophoretic techniques for analytical protein separations are state of the art. In spite of many advances in this field by precast ultrathin gels and automatization this technique is very time consuming. To overcome both problems of ELISA and electrophoresis techniques as well, we employed RP-HPLC as a rapid tool for controlling ATIII concentrations in cell culture supernatant and also for detection of main impurities during purification.

\section{Experimental}

\subsection{Cell culture}

A recombinant Chinese hamster ovary ( $\mathrm{CHO}$ ) cell line (SS3-A2) producing human active recombinant ATIII (rATIII) [4] was cultivated in a 2-1 bench-scale stirred tank bioreactor (Biostat MD2, B. Braun Biotech International, Melsungen, Germany). The cells were propagated in a serum-free standard medium (Dulbecco's Modified Eagle Medium and Ham's Fi2, 1:1 mixture) (Gibco, Paisley, UK) [5] supplemented with ethanolamine $(150 \mu \mathrm{mol} / 1)$, glucose $(5.5 \mathrm{mmol} / \mathrm{l})$ and amino acids in various concentrations. As protein additives the medium contained human transferrin (HT) $(10 \mathrm{mg} / \mathrm{l})$ (Behringwerke, Marburg, Germany), bovine in- sulin (IN) (10 mg/l) (Sigma, Deisenhofen, Germany) and lipoproteins (Excyte I, Bayer Diagnostic, Munich, Germany) (1 ml/l).

The reactor was equipped with a fixed aeration basket carrying $10 \mathrm{~m}$ of silicone tubing for bubble free aeration [6]. The reactor vessel was connected to two reservoirs via two peristaltic pumps (101 UR/32, Watson Marlow, Falmouth, UK). One of the reservoirs was filled with complete serum-free medium, the other with a 5 -fold concentrate of medium substrates (glucose, amino acids, etc.). $\mathrm{pO}_{2}$ in the reactor was monitored with a $\mathrm{pO}_{2}$ probe (Ingold, Steinbach, Germany) and controlled by feeding nitrogen or cxygen, respectively, into the continuous aeration stream of air. $\mathrm{pH}$ was monitored with a $\mathrm{pH}$ electrode (Ingold, Steinbach, Germany) and controlled by fecding $\mathrm{CO}_{2}$ into the aeration stream. The bioreactor parameters were set as follows: $\mathrm{pO}_{2} 40 \%$ air saturation, $\mathrm{pH} 7.1$, stirrer speed $65 \mathrm{rpm}$, temperature $37^{\circ} \mathrm{C}$. The seed cells were prepared in T-flasks and spinncr systems.

At the end of the cultivation the culture broth was stored at $4^{\circ} \mathrm{C}$ overnight to let the cells settle. Then, the supernatant was decanted and 0.45$\mu \mathrm{m}$ filtrated before purification to remove the remained particles.

\subsection{Downstream processing}

The purification of rATIII was done by a three step procedure of ion exchange ciltromatography, affinity chromatography and gel filtration. In order to bind rATIII to the anion exchanger the conductivity of the supernatant had to be reduced from $13 \mathrm{mS} / \mathrm{cm}$ to about $1-1.5 \mathrm{mS} / \mathrm{cm}$ by diafiltration with a $M_{\mathrm{r}} 10000$ membrane (S10Y10, Amicon, Berverly, MA, USA). After adjusting the $\mathrm{pH}$ to 7.0, the supernatant first was filtrated $(0.2 \mu \mathrm{m})$ to remove particles and then passed through a preparative membrane ion-exchange unit. The ion-exchange step was performed with a strongly basic Sartobind membrane ion-exchange module with a filtration area of $2400 \mathrm{~cm}^{2}$, which was kindly supplied by Sartorius (Göttingen, Germany). The procedure for this step is published in detail elsewhere [7]. 
it he affinity matrix was heparin (Sigma) coupled to controlled pore glass (Schott, Mainz, Germany). The coupling procedure is described elsewhere [8]. A 50-ml volume of heparin-controlled pore glass was used in a XK 50/30 column (Pharmacia Biosystems, Freiburg, Germany). Final purification was carried out using a preparative gel permeation column (Superdex 200 PG; Pharmacia Biosystems) with a gel volume of $600 \mathrm{ml}$.

Buffers: for the basic membrane ion exchanger a buffer system of (A) $20 \mathrm{~m} M$ Tris $\cdot \mathrm{HCl}(\mathrm{pH} 7)$ and (B) $20 \mathrm{~m} M$ Tris $\cdot \mathrm{HCl}-250 \mathrm{~m} M \mathrm{NaCl}$ (pH 7) was used. For the affinity chromatography the buffer system was (A) $2.0 \mathrm{mM}$ 4-(2-hydroxyethyl)-1-piperazine-ethanesuiphonic acid (HEPES)-150 $\mathrm{mM} \mathrm{NaCl}(\mathrm{pH} \mathrm{5.8)}$ and (B) 20 $\mathrm{m} M$ HEPES-2.5 $M$ NaCl (pH 7). For gel permeation a $20 \mathrm{~m} M$ sodium phosphate-150 $\mathrm{m} M$ $\mathrm{NaCl}(\mathrm{pH} \mathrm{7)}$ buffer was used.

\subsection{Analytical methods}

rATIII concentrations were determined by HPLC. The chromatographic system was a fully computer-controlled Kontron HPLC workstation with DS450-MT2 software (Kontron, Neufahrn, Gcrmany) consisting of two pumps type 420, a high-pressure mixing chamber, an autosampler type 465 (all Kortron) and a spectrofluorimeter RF 551 (Shimadzu, Duisburg, Germany). The spectrofluorimeter was set to an excitation wavelength of $280 \mathrm{~nm}$ and emission was monitored at $340 \mathrm{~nm}$. The HPLC column used in this study was a $50 \mathrm{~mm} \times 4.6 \mathrm{~mm} \mathrm{I.D.} \mathrm{C}_{4}$ reversed-phase column (type 214TP5405, Vydac, Hesperia, CA, USA) with $5 \mu \mathrm{m}$ particle size and $30 \mathrm{~nm}$ pore size. For the separation a binary gradient (gradients are discussed below in detail) was used with following eluents: eluent $\mathrm{A}$ : water-acetonitrile $(87.5: 12.5, \mathrm{v} / \mathrm{v})$ with $0.01 \%$ trifluoroacetic acid (TFA); cluent $B$ : acetonitrile-water $(70: 30$, $v / v)$ with $0.08 \%$ TFA. Pure water was prepared with a Milli-Q system (Millipore, Eschborn, Germany), acetonitrile was of HPLC quality and TFA was of quality used for protein sequencing (both Merck, Darmstadt, Germany).

To control and verify the HPLC data rATIII concentrations in the samples were also determined by a kinetic sandwich ELISA method (Behringwerke). it was necessary to dilute samples 1:50 to $1: 500$ (for fermentation samples) or higher (for samples from purification steps) to have the correct scale range of the ELISA.

Purity was determined by sodium dodecyl sulphate-polyacrylamide gel clectrophoresis (SDS-PAGE) [9] automatically (Phast-System, Pharmacia Biosystems) using silver staining [10]. The silver-stained gels were scanned using an Epson fiat bed scanner GT6000 and the GelImage 1DEVA software (Pharmacia Biosystems).

\section{Results}

\subsection{Calibration}

For quantification of both proteins rATIII and HT as well response factors corresponding to integrated peak area were used. The response factor for rATIII was investigated in the following way. rATIII was purified from serum-free supernatant to a purity higher than $99 \%$ with methods described above. The final elution from the gel permeation step was quantified with the ATIII-ELISA at several dilution steps. Then, several calibration runs with different dilutions of that solution were made by HPLC. From this calibration curve the response factor for rATIII was calculated. This procedure was necessary because purified human ATIII could not be purchased in correct quality and sufficient amounts. The response factor for HT was obtained by analysing several dilutions of a stock solution of HT which was also used for supplementation of the serum-free medium. For rATIII an on-column amount in the range from 0.1 to $1 \mu \mathrm{g}$ ATIII gave a linear response with a response factor of 23.93 units per $\mu \mathrm{g}$ (relative peak area). A linear response for an on-column range of 0.1 to $0.5 \mu \mathrm{g}$ with a response factor of 25.65 units per $\mu \mathrm{g}$ could be determined for HT. The range for HT had not to be extended to higher amounts because maximal concentration of HT in fermentation and purification samples 


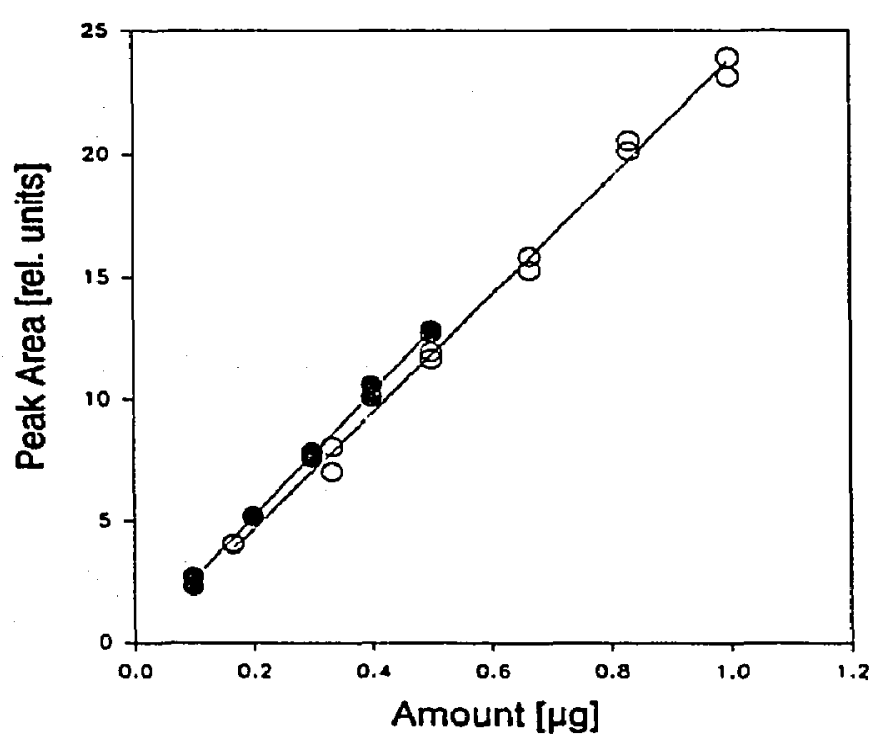

Fig. 1. Calibration curves for recombinant human antithrombin III (O) and buman transferrin (O). An on-column amount from 0.1 to $1 \mu \mathrm{g}$ ATIIl gave a linear response with a response factor of 23.93 units per $\mu \mathrm{g}$ (relative peak arca). A linear response for an on-column range of 0.1 to $0.5 \mu \mathrm{g}$ with a response factor of 25.65 units per $\mu \mathrm{g}$ could be determined for HT.

never exceeded this range. In Fig. 1 the calibration curves for rATIII and HT are shown. The reproducibility of the method was evaluated by repeated analyses of a mixture of an aqueous solution of HT $(10.0 \mathrm{mg} / \mathrm{l})$ and ATIII (16.65 $\mathrm{mg} / \mathrm{l})$. The solution was injected 14 times showing a result for $\mathrm{HT}$ of $10.31 \pm 0.63 \mathrm{mg} / \mathrm{l}$ and for ATIII of $16.48 \pm 0.66 \mathrm{mg} / \mathrm{l}$, respectively.

\subsection{Separation}

For the separation of rATIII and HT on the RP column a special elution profile had to be developed. The proteins occurring in fresh serum-free medium are insulin, human transferrin, small amounts of lipoprotein and sometimes an additional amount of bovine serum albumin up to $1 \mathrm{~g} / 1$. In cell culture supernatant rATIII and smaller amounts of some other proteins formed by secretion or cell lysis are also present. Because of the rapid degradation of insulin in cell culture broth $[11 \mathfrak{j}$, this protein can only be detected in the supernatant in very small amounts which cannot be quantified.
In order to perform a good resolution for rATIII quantification the following profile was used: 0 to $1 \mathrm{~min} 100 \%$ eluent $A, 1$ to $5 \mathrm{~min}$ linear gradient 0 to $48 \%$ eluent $B, 5$ to $12.5 \mathrm{~min}$ linear gradient 48 to $65 \%$ eluent B, 12.5 to 14 min linear gradient 65 to $100 \%$ eluent B, 3 min $100 \%$ eluent B. Fig. 2 shows a typical chromatogram with this multi-step elution profile resulting in a satisfactory separation.

rATIII was also quantified in cell culture supernatant containing up to $10 \%$ fetal bovine serum (FBS). In this case the elution profile was changed regarding the great variety of proteins present in very different concentrations. The total amount of proteins in medium containing $10 \%$ FBS is about $4 \mathrm{~g} / 1$ in respect to serum-free medium with about $30 \mathrm{mg} / \mathrm{l}$ as described above. In Fig. 3 the chromatograms of separations of fresh medium with 5\% FBS and supernatant of ATIII-CHO cells at the end of a batch are shown. The rATIII peak corresponds to a concentration of $20 \mathrm{mg} / \mathrm{l}$.

A column regeneration step was performed

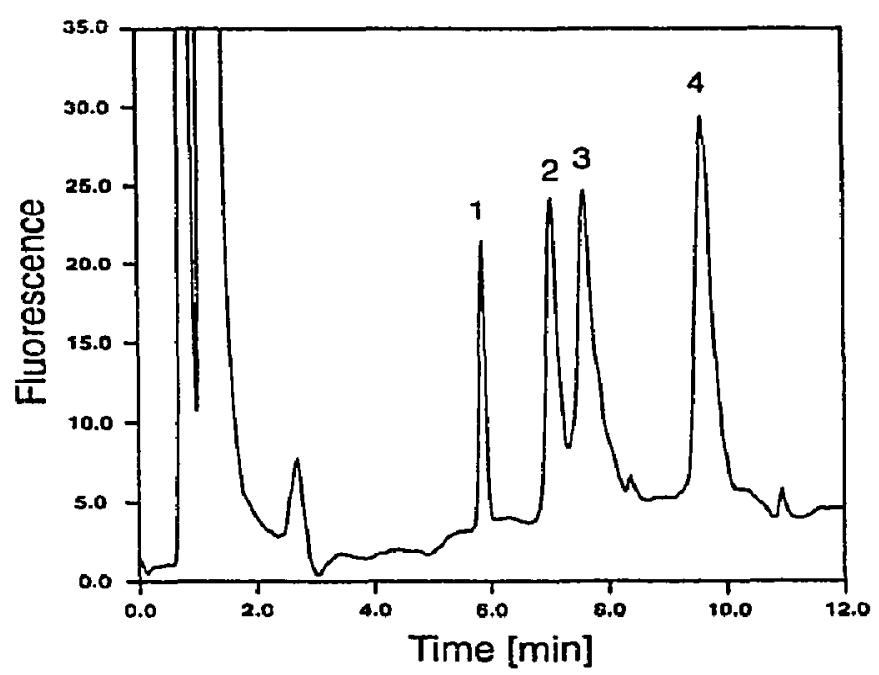

Fig. 2. Chromatogram of a protein separation from cell culture mediur with a multi-step elution profite. Yeaks: $1=$ insulin (injected amount $0.75 \mu \mathrm{g}$ ) $; 2=$ human transferrin $(0.2 \mu \mathrm{g}) ; 3=$ bovine albumin $(0.2 \mu \mathrm{g}) ; 4=$ recombinant human antithrombin III $(0.33 \mu \mathrm{g})$. The following elution profile was used: 0 to 1 min $100 \%$ eluent $A, 1$ to 5 min linear gradient 0 to $48 \%$ eluent $B, 5$ to $12.5 \mathrm{~min}$ linear gradient 48 to $65 \%$ eluent $\mathrm{B}, 12.5$ to $14 \mathrm{~min}$ linear gradient 65 to $100 \%$ eluent $\mathrm{B}, 3 \mathrm{~min} 100 \%$ eluent $\mathrm{B}$. 

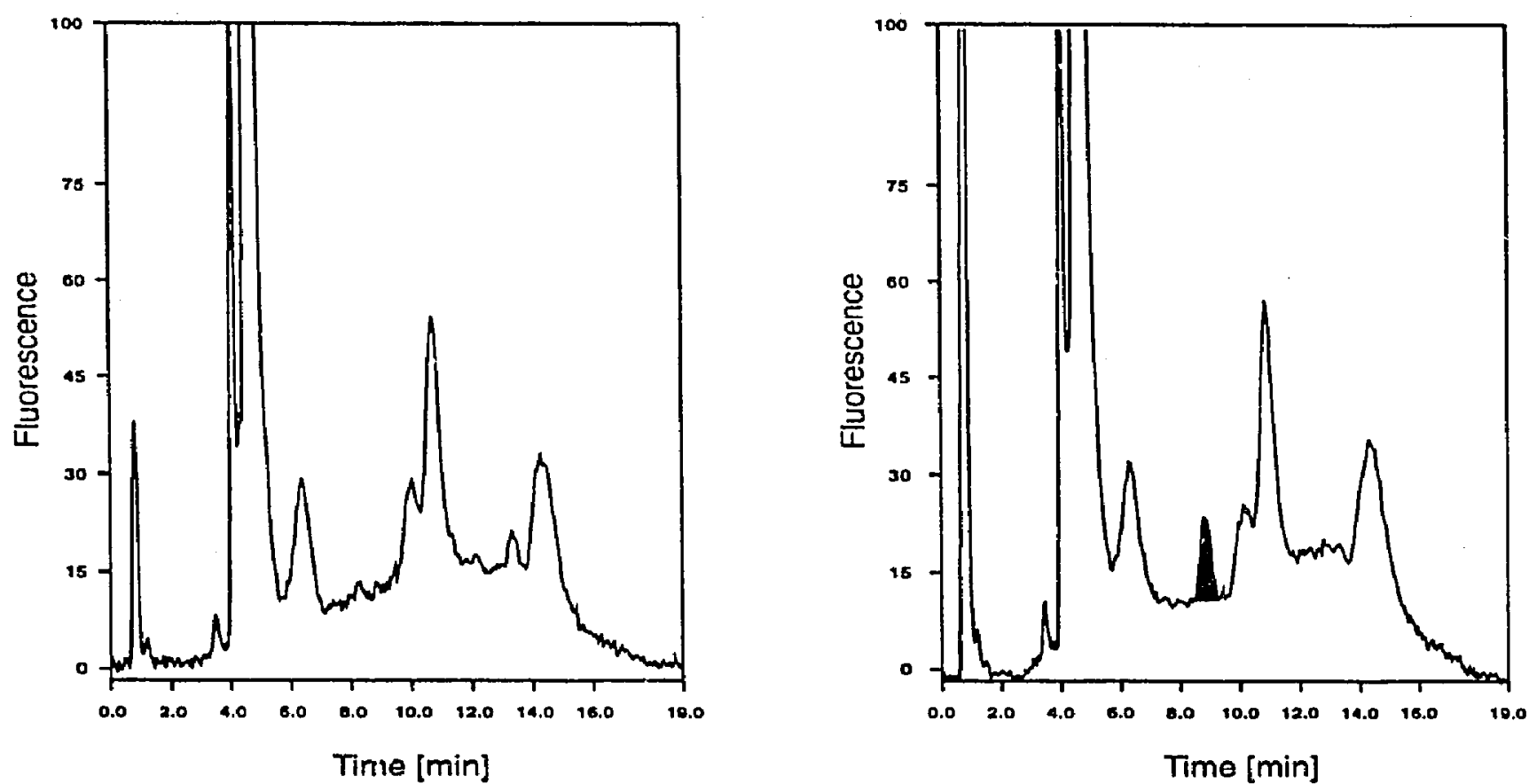

Fig. 3. Elution profile of protein separations of cell culture medium and cell culture supernatant each containing $5 \%$ fetal bovine serum. (Left) Fresh medium before cultivation; (right) cell culture medium at end of a CHO batch cultivation. The peak marked in black corresponds to an ATIIl concentration of $20 \mathrm{mg} / 1$.

every 5 to 15 samples depending on total protein content of the samples. The column was washed with buffer $B$ for $10 \mathrm{~min}$ and reequilibrated with one gradient elution without injection. Prior to injection each sample was passed through a $0.45-$ $\mu \mathrm{m}$ membrane filter to remove particles. Using these precautions the lifetime of the column could be exceeded to more than 500 sample runs. During this time the elution quality varied only slightly with irregularities during elution buffer preparation. After each buffer change the system was calibrated. The calibration data were compared with previous calibrations and stored for later coiamn evaluation.

\subsection{Monitoring a fermentation}

A 18-day fed batch process was monitored for produci (rATIII) concentration with both analytical methods, ELISA and RP-HPLC. Fig. 4 shows the time course of this cultivation. The cells were seeded at a cell density of $1.8 \cdot 10^{5}$ cells $/ \mathrm{ml}$ in 0.51 reactor volume and cultivated in batch mode for four days until the cell growth rate decreased. A cell density of $7 \cdot 10^{5}$ cells $/ \mathrm{ml}$ was reached. Then, the fed batch procedure was started by feeding complete serum-free medium into the reactor vessel. First, the cell growth rate increased, but three days later (days 7 and 8) cell growth stopped again indicating limitation of nutrients. Therefore, at day 8 , the second feeding stream of a 5-fold substrate enriched medium was activated. Cells growth started again, reaching a final amount of $1.3 \cdot 10^{9}$ cells in the bioreactor. This level of cells occurred because of nutrient limitation (data not shown). The feeding rate of medium and concentrate was not high enough to satisfy the cells for further cell growth. Nevertheless, the production of rATIII never stopped, reaching a final amount of about $90 \mathrm{mg}$ rATIII in the bioreactor which corresponds to a concentration of $52 \mathrm{mg}$ rATIII per litre. From Fig. 4 it can be seen that the ATIII measurements with RP-HPLC and ELISA correlate very well. Only at higher concentrations the values aiffered considerably which can be explained by 

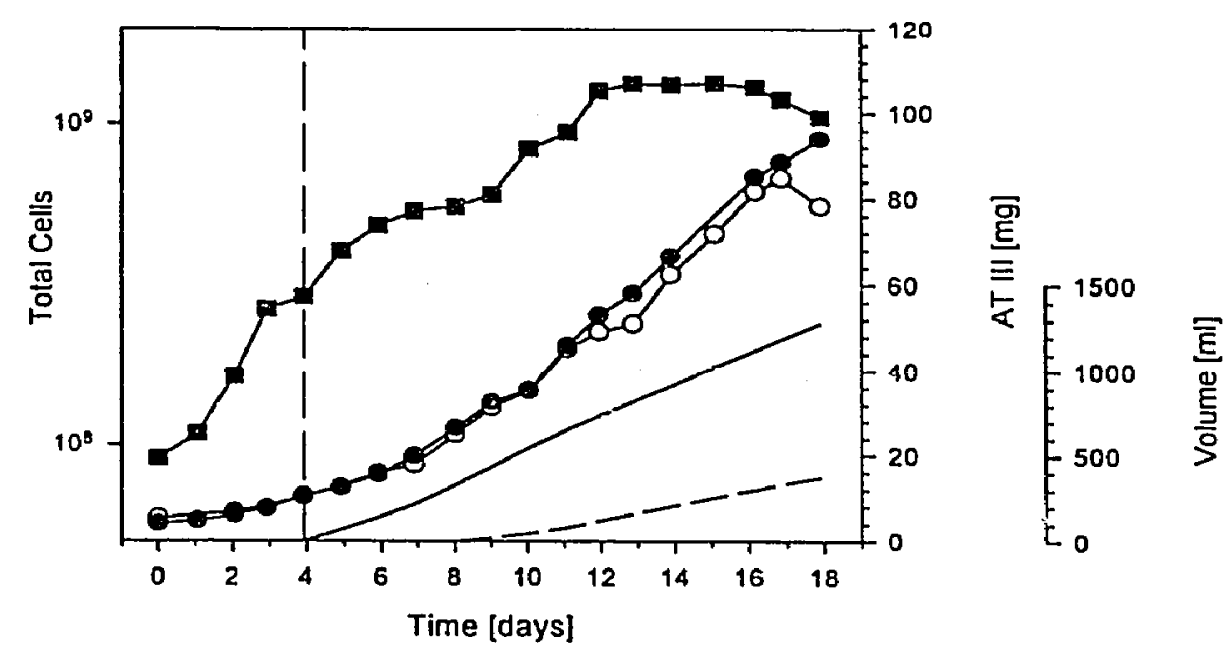

Fig. 4. Time course of a fed batch cultivation process of CHO cells producing rATIII. $\mathbf{a}=$ Total cell concentration in the bioreactor; $=$ ATIII amount in the bioreactor determined with RP-HPLC; $O=A T I I$ anisount analyzed with ELISA method; solid line = cumulative fecding volume of complete medium; broken line = cumulative fecding volume of concentrated medium.

the incorrectness of the ELISA method using higher predilutions for increasing concentrations. For the RP-HPLC it was not necessary to prepare the samples in any way except ce!l removal. Cell free supernatant was applied directly to the HPLC column. That made the use of RP-HPLC determination much more faster and much easier than the ELISA method.

\subsection{Monitoring the downstream processing}

Table 1 shows a comparison between RPHPLC and gel electrophoresis methods for the determination of total protein content after the subsequent process steps. After reducing the ionic strength by diafiltration rATIII was rapid concentrated by a strong basic membrane ionexchange siep to reduce the water. During this step HT concentration was reduced from 23.1 to $5.1 \%$ total protein content (measured by RPHPLC). But other proteins, especially in the low-molecular-mass area, were concentrated. The next purification step of rATIII was carried out by affinity chromatography with heparin coupled to controlled pore glass [8]. The purity increased in this step trom 58.2 to $83.4 \%$ total protein content. The concentration of rATIII in the eluate increased to $1.3 \mathrm{~g} / \mathrm{l}$. The preparative

Table 1

Downstream processing of rATIIl of a serum-free cultivation

\begin{tabular}{|c|c|c|c|c|c|c|}
\hline \multirow[t]{2}{*}{ Method } & \multicolumn{2}{|l|}{ AT III $(\%)$} & \multicolumn{2}{|l|}{$\mathrm{HT}(\%)$} & \multicolumn{2}{|l|}{ Others $(\%)$} \\
\hline & RP-HPLC & Gel-Image & RP-HPLC & Gel-Image & RP-HPLC & Gel-Image \\
\hline Bioreactor & 57.2 & n.d. & 23.1 & n.d. & 19.7 & n.d. \\
\hline Membrane ion exchange & 58.2 & n.d. & 5.1 & n.d. & 36.7 & n.d. \\
\hline Heparin affinity chromatography & 83.4 & 72.7 & 3.9 & 3.4 & 12.7 & 23.9 \\
\hline Gel permeation & 100 & 100 & 0 & 0 & 0 & 0 \\
\hline
\end{tabular}

The total protein content after the subsequent purification steps is shown, determined by RP-HPLC and in comparison to gel electrophoresis and scanning with Gel-Image system; n.d. = not determined. 
gel permeation step led to a purity of $100 \%$. Contaminants were neither detected by gel electrophoresis nor by RP-HPLC. Fig. 5 shows the eluates of the different purification steps on a SDS-polyacrylamide gradient gel (8-25\%) detected with a modified silver stain under unreduced conditions.

The advantage of RP-HPLC detection of rATIII Juring downstream processing is the rapidity and the possibility of detection and quantification of impurities. The detection limit of the employed gel electrophoresis methods with silver staining is $0.1 \mathrm{ng}$ per lane [12] and for routine analysis $>1 \mathrm{ng} /$ lane whereas with $\mathrm{RP}$ HPLC an on-column amount of approximately $100 \mathrm{ng}$ can be quantified. However, the long time needed for ELISA and gel electrophoresis

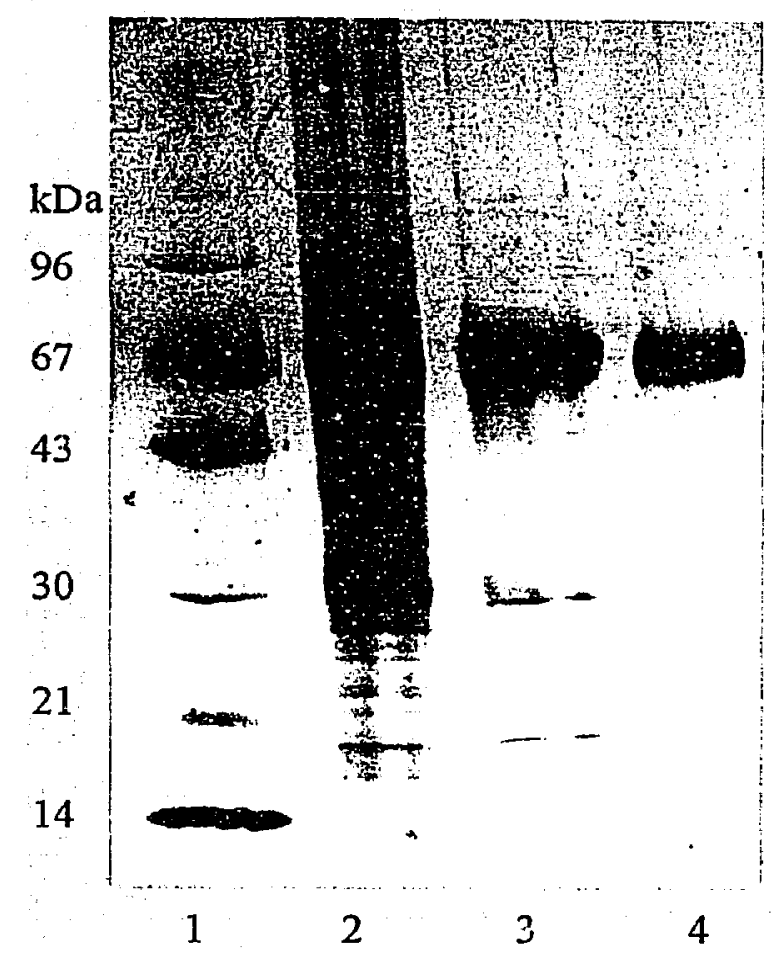

Fig. 5. SDS-polyacrylamide gradient gel (8-25\%) using a modified silver stain under unreduced conditions. Lanes: $1=$ marker, $\quad M_{1}=14000-96000 \quad$ (reduced) $\quad(\mathrm{kDa}=$ kilodalton); 2 = clution fraction after membrane ion-exchange stcp; 3 = clution fraction after affinity chromatography; $4=$ elution fraction after gel permeation (pure rATIII). is reduced to a duration of about $25 \mathrm{~min}$ per sample. Because of this fast availability of analytical results the development of new purification methods is simplified. Chromatographic results such as capacity, concentration factor and purity are now available half an hour after each purification step.

\section{Conclusions}

With the presented RP-HPLC method a fast and reliable tool was developed for the quantitative determination of human antithrombin III in cell culture supernatant and other media including eluates from various purification steps. The devaloped separation procedure on a reversedphase column $\left(\mathrm{C}_{4}\right)$ allowed also a quantification of human transferrin and insulin without any changes.

\section{Acknowledgements}

We thank Behringwerke AG (Marburg, Germany) for kindly supplying the $\mathrm{CHO}$ cell line and the ATIII immunoassay. This work was supported in part by the project "Development of a procedure and a plant for the recirculation of nutrient media for animal cell culture" (BMFT ref No. 0319346A) of the Germar Ministry of Research.

\section{References}

[1] C.H. Beresford and M.C. Owen, Int. J. Biochem., 22 (1990) 121 .

[2] U. Abildgaard, Scand. J. Clin. Lab. Invest., 19 (1967) 190.

[3] M. Miller-Andersen, H. Borg and L.O. Andersen, Thromb. Res., 5 (1974) 439.

[4] G. Zettimcissl, H. Ragg and H. Karges, Biotechnology, 5 (1987) 720.

[5] H. Büntemeyer, D. Lülkemeyer and J. Lehmann, Cytotechnology, 5 (1991) 57.

[6] W. Kuhlmann, Dev. Biol. Standard., 66 (1987) 263. 
[7] D. Lütkemeyer, M. Bretschneider, H. Büntemeyer and J. Lehmann, J. Chromatogr., 639 (1993) 57.

[8] M. Bretschneider, D. Lütkemeyer and J. Lehmann, Paper presented at the 11. DECHEMA Jahrestagung der Biotechnologen, Nürnberg, 1993, 437.

[9] Lämmli, Nature, 227 (1970) 680.
[10] J. Heukeshoven, R. Dernick and B. J. Padola, Elektrophorese-Forum '86, Technische Universität München, Munich, 1986, p. 107.

[11] G. Hewlett, Cytotechnology, 5 (1991) 3.

[12] J. Heukeshoven and R. Dernick, Electrophoresis, 9 (1988) 28. 